Article

\title{
Stability Analysis of Grid-Connected Photovoltaic Systems with Dynamic Phasor Model
}

\author{
Md Rasel Mahmud * (D), Ahmed F. Abdou (D) and Hemanshu Pota \\ School of Engineering and Information Technology, The University of New South Wales, \\ Canberra, ACT 2612, Australia \\ * Correspondence: mdrasel.mahmud@student.adfa.edu.au
}

Received: 24 May 2019; Accepted: 29 June 2019; Published: 2 July 2019

check for updates

\begin{abstract}
The typical layout of power systems is experiencing significant change, due to the high penetration of renewable energy sources (RESs). The ongoing evaluation of power systems is expecting more detailed and accurate mathematical modeling approaches for RESs which are dominated by power electronics. Although modeling techniques based on state-space averaging (SSA) have traditionally been used to mathematically represent the dynamics of power systems, the performance of such a model-based system degrades under high switching frequency. The multi-frequency averaging (MFA)-based higher-index dynamic phasor modeling tool is proposed in this paper, which is entirely new and can provide better estimations of dynamics. Dynamic stability analysis is presented in this paper for the MFA-based higher-index dynamical model of single-stage single-phase (SSSP) grid-connected photovoltaic (PV) systems under different switching frequencies.
\end{abstract}

Keywords: renewable energy source; power electronic interface; multi-frequency averaging; dynamic phasor; switching frequency sensitivity; grid-connected photovoltaic systems

\section{Introduction}

In recent years, renewable energy sources (RESs) have been gaining more attention worldwide due to their environmentally friendly operations and the variable prices of fossil fuels. The photovoltaic (PV) generation system is becoming one of the most popular RESs as it generates electricity from naturally available sunlight [1]. In the literature, there are two modes of operation, stand-alone and grid-connected, where the latter one is more convenient as it reduces the cost of installing energy storages than the former. Furthermore, there are initiatives from both local and federal governments for the integration of grid-connected solar PV systems, which have resulted in more rooftop PV systems in recent years. As a result, households produce more power than they require, and supply the extra power to the utility grid. The grid integration of solar PV systems heavily relies on power electronic interfaces (PEIs) and hence, there exist more harmonics due to the presence of PEIs.

The ongoing interactions between PEIs and RESs introduce new barriers related to stability and control issues [2-4]. For the stability analysis of any system, which is a preliminary assessment of its reliable operation, small- and large-signal analyses are widely used. In addition, time-domain detailed switch simulation tools provide useful insights to outturn small-signal behaviors of PEIs [5]. The drawback of such type analysis is being unable to provide proper transient behavior estimation of PEIs. Furthermore, the characterizations of PEIs to estimate instability situations require extensive simulations, which are time-consuming.

The electromagnetic transient (EMT) program and quasi-steady-state approximations are the available simulation tools for the power system, including advanced and compact PEIs [6]. The EMT program has been widely accepted at industry level for the dynamic simulation of systems and controllers $[7,8]$; however, the usage of this software is quite tricky and time-consuming for large 
networks [9]. Moreover, the quasi-steady-state approximation models are generally useful for systems with electro-mechanical transients. However, these types of tools do not work for systems with fast electromagnetic transients e.g., power electronic converters with high-frequency switches [10].

Most of the literature on the grid-connected PV systems is modeled based on the state-space averaging (SSA) technique to design the switching control inputs for converters [11-14]. In the single-stage grid-connected PV system, a voltage source inverter (VSI)-type power electronic converter converts DC power to AC power and injects this AC power into the utility grid. It may not be possible to capture the higher-index nonlinearities of the VSI by conventional SSA approaches, as these approaches only address zero indexes of state variables $[15,16]$. Due to this limitation of existing techniques, the nonlinear switching function-based VSI highly demands an approach for convenient mathematical representation, which will have the capability to include the remaining higher index.

The switching frequency-sensitive MFA-based dynamic phasor approach provides a detailed mathematical representation of the dynamical system, which is able to address DC, fundamental, and other harmonic components of the state variable in the form of Fourier series [16]. However, this modeling technique provides negligible flexibilities for harmonic components which have no considerable impact on state variables. Moreover, it is provided with a conventional state-space model where the involvement of fundamental and harmonic components is not under consideration. The MFA-based dynamic phasor modeling technique is able to provide a detailed model of PEIs [15-18], flexible AC transmission system [19,20], electrical machines [21,22] and other active parts of the power systems. The dynamic phasor-based mathematical model of single-stage and two-stage grid-connected inverter system is proposed in $[23,24]$, where the generation side acts as an ideal DC source. However, the grid-connected VSI associated with RESs is a more practical problem.

This paper aims to represent a detailed dynamic phasor model of the SSSP grid-connected PV system for DC and fundamental components. The other novelty of this paper includes the active state during the capacitance rather than existing grid-connected VSI systems. The eigenvalues and stability analysis of the dynamic phasor model are also investigated which is an essential assessment for every dynamic system. The assessment was done for different switching frequencies that may provide a better understanding of the sensitivity for the switching frequency of the VSI.

The remaining parts of this paper will present in the following sequence. The dynamical model for an SSSP grid-connected PV system is presented in Section 2. Section 3 shows the fundamental phenomena associated of the dynamic phasor. The dynamic phasor model of the SSSP grid-connected PV system shown in Section 4. Section 5 explains the analysis of the eigenvalues of the proposed dynamic system under different switching frequencies. Section 6 represents the performance analysis of the proposed modeling technique under time and frequency domain. Finally, the paper summarizes with future works in Section 7.

\section{Dynamical Model of the SSSP Grid-Connected PV System}

This section presents the dynamic mathematical model of the proposed SSSP grid-connected PV system as shown in Figure 1. The schematic circuit diagram of the proposed system as shown in Figure 1 includes a PV array which is connected to the grid through a DC-link and a single-phase full-bridge VSI used for transferring the DC power from the PV system to the AC grid.

In Figure 1, $v$ is the output voltage of PV array which is also the voltage across to the DC-link capacitor $C$ and $i_{p v}$ is the output current of the solar array while $u_{1}, u_{2}, u_{3}$, and $u_{4}$ are the four switches of the inverter. At the output-side of the single-phase full-bridge inverter, $R$ and $L$ are the line resistance and the combination of filter-line inductance, respectively. The grid current is $\imath$ and voltage $e(t)=V_{m} \sin (\omega t)$ where $V_{m}$ denotes the amplitude of the grid voltage. The angular frequency is $\omega=2 \pi f$ where $f$ is the grid frequency. When $u_{1}$ and $u_{4}$ are ON, in Figure $1 u_{2}$ and $u_{3}$ are OFF. In this situation, and Kirchhoff's voltage and current laws, i.e., KVL and KCL, can be applied to obtain the following dynamical equations [11,12]: 


$$
\begin{gathered}
\frac{d v}{d t}=\frac{1}{C}\left(\imath_{p v}-\imath\right) \\
\frac{d \imath}{d t}=\frac{1}{L}(v-R \imath-e)
\end{gathered}
$$

When $u_{1}$ and $u_{4}$ are OFF, and $u_{2}$ and $u_{3}$ are ON. In this situation, and Kirchhoff's voltage and current laws, i.e., KVL and KCL can be applied to obtain the following dynamical equations:

$$
\begin{gathered}
\frac{d v}{d t}=\frac{1}{C}\left(\imath_{p v}+\imath\right) \\
\frac{d \imath}{d t}=\frac{1}{L}(v+R \imath-e)
\end{gathered}
$$

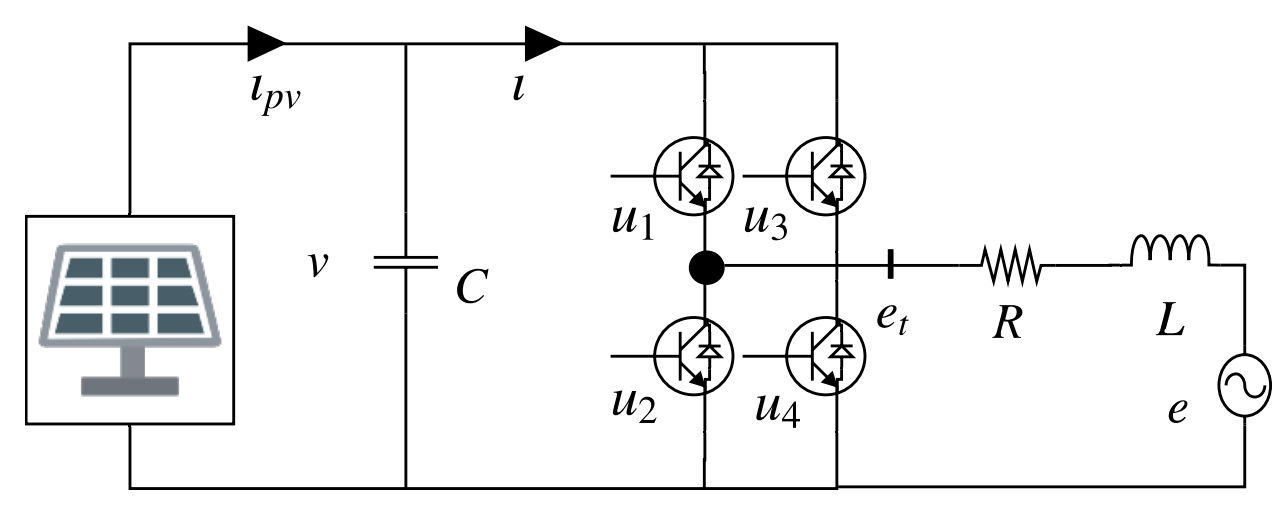

Figure 1. Schematic circuit diagram of SSSP grid-connected PV system.

Finally, by applying the averaging technique, Equations (1)-(4) can be written as follows:

$$
\begin{gathered}
\frac{d v}{d t}=\frac{1}{C}\left(\iota_{p v}-u \imath\right) \\
\frac{d \imath}{d t}=\frac{1}{L}(v u-R \imath-e)
\end{gathered}
$$

The final average model of the SSSP grid-connected PV system as represented by Equations (5) and (6) can be used to develop the corresponding dynamical phasor model. The fundamentals associated with the dynamic phasor modeling is discussed in the following section before developing the dynamic phasor model of the SSSP grid-connected PV system.

\section{Fundamentals of the Dynamic Phasor Analysis}

This section provides a brief overview of the MFA-based dynamic phasor modeling [16]. The fundamental idea of the dynamic phasor technique is the representations of the differential equations characterizing the dynamics of a nonlinear system in the forms of the corresponding Fourier coefficients of almost, but not precisely, periodic sinusoidal waveforms. These equations are linear with higher dimensions as compared to the dynamical equations which include nonlinear switching functions. Some basic definitions of the terms used in the dynamic phasor are presented here.

The Fourier transform of an almost periodic waveform $x(\tau)$, can be written as: 


$$
x(\tau)=\sum_{k=-\infty}^{+\infty} \bar{x}_{k}(t) e^{j k \omega_{s} \tau}
$$

with

$$
\bar{x}_{k}(t)=\frac{1}{T} \int_{t-T}^{t} x(\tau) e^{-j k \omega_{s} \tau} d \tau
$$

where $\omega_{s}=2 \pi / T$ and $\bar{x}_{k}(t)$ represents the complex Fourier coefficients, which define phasors. From the above definition, the key equation for the $k$ th Fourier coefficient can be written as follows:

$$
\frac{d}{d t} \bar{x}_{k}(t)=\frac{\overline{d x}_{k}}{d t}(t)-j k \omega_{s} \bar{x}_{k}(t)
$$

If the change in the $k$ th Fourier coefficient, i.e., $\frac{\overline{d x}_{k}}{d t}(t)$ is neglected; Equation (9) demonstrates the well-known phasor relationship. In practice, imaginary and real parts of dynamic phasor equations can be separated to obtain a system of differential equations.

Another critical property of the dynamic phasor is the computation of the product of two signals or variables. The index-k average of the product of variables $x(t)$ and $y(t)$ can be computed as follows

$$
\overline{x y}_{k}=\sum_{m=-\infty}^{\infty} \bar{x}_{k-m} \bar{y}_{m}
$$

where $m$ is the sum of all integers. If the state variables $x(t)$ and $y(t)$ and their index- 0 and index- 1 carry almost whole properties of a state, other higher indices can be neglected to avoid the complexity.

$$
\begin{aligned}
& x(t) \approx \bar{x}_{0}+\bar{x}_{-1} e^{-j \omega_{s} t}+\bar{x}_{1} e^{j \omega_{s} t} \\
& y(t) \approx \bar{y}_{0}+\bar{y}_{-1} e^{-j \omega_{s} t}+\bar{y}_{1} e^{j \omega_{s} t}
\end{aligned}
$$

Hence, Equation (10) can be simplified as follows:

$$
\begin{gathered}
\overline{x y}_{0}=\bar{x}_{0} \bar{y}_{0}+\bar{x}_{1} \bar{y}_{-1}+\bar{x}_{-1} \bar{y}_{1} \\
\overline{x y}_{-1}=\bar{x}_{-1} \bar{y}_{0}+\bar{x}_{0} \bar{y}_{-1} \\
\overline{x y}_{1}=\bar{x}_{1} \bar{y}_{0}+\bar{x}_{0} \bar{y}_{1}
\end{gathered}
$$

Furthermore, all higher indices except index-0 have two parts: positive and negative which are complex conjugates of each other and, whose are written as:

$$
\begin{aligned}
& \bar{x}_{1}=\bar{x}_{1}^{R}+j \bar{x}_{1}^{I}=\bar{x}_{-1}^{*}=\left(\bar{x}_{-1}^{R}+j \bar{x}_{-1}^{I}\right)^{*} \\
& \bar{y}_{1}=\bar{y}_{1}^{R}+j \bar{y}_{1}^{I}=\bar{y}_{-1}^{*}=\left(\bar{y}_{-1}^{R}+j \bar{y}_{-1}^{I}\right)^{*}
\end{aligned}
$$

where the superscripts, $R$ and $I$ define the real and imaginary parts of complex conjugates. Using Equations (16) and (17), Equations (13)-(15) can be rewritten as follows:

$$
\begin{gathered}
\overline{x y}_{0}=\bar{x}_{0} \bar{y}_{0}+2\left(\bar{x}_{1}^{R} \bar{y}_{1}^{R}+\bar{x}_{1}^{I} \bar{y}_{1}^{I}\right) \\
\overline{x y}_{1}^{R}=\bar{x}_{0} \bar{y}_{1}^{R}+\bar{x}_{1}^{R} \bar{y}_{0}
\end{gathered}
$$




$$
\overline{x y}_{1}^{I}=\bar{x}_{0} \bar{y}_{1}^{I}+\bar{x}_{1}^{I} \bar{y}_{0}
$$

The relationships as discussed in this section are used to develop the dynamic phasor model based on the average model of the VSI in the SSSP grid-connected PV systems. The detailed dynamic phasor modeling of the SSSP grid-connected PV system is discussed in the following section.

\section{Dynamic Phasor Modeling of the SSSP Grid-Connected PV System}

In this section, the MFA-based dynamic phasor model of the proposed system been developed for the DC and fundamental components of the state variables where $k=\overline{\overline{1}}(k=\overline{\bar{n}}=$ index 0 to index $n)$. The step-by-step averaging scheme for the SSSP grid-connected PV system is presented in a simplified way here to obtain the dynamic phasor model.

The average model of the SSSP grid-connected system (5) and (6) can be derived for an index-0 as follows:

$$
\begin{gathered}
\frac{d \bar{v}_{0}}{d t}=\frac{1}{C}\left(\iota_{p v}-\overline{\imath u}_{0}\right) \\
\frac{d \bar{i}_{0}}{d t}=\frac{1}{L}\left(\overline{v u}_{0}-R i_{0}-e\right)
\end{gathered}
$$

Substituting (18) into (21) and (22), these equations becomes as follows:

$$
\begin{gathered}
\frac{d \bar{v}_{0}}{d t}=\frac{1}{C}\left(\imath_{p v}-\bar{\imath}_{0} \bar{u}_{0}+2 \bar{\imath}_{1}^{R} \bar{u}_{1}^{R}++2 \bar{\imath}_{1}^{I} \bar{u}_{1}^{I}\right) \\
\frac{d \bar{i}_{0}}{d t}=\frac{1}{L}\left(\bar{v}_{0} \bar{u}_{0}+2 \bar{v}_{1}^{R} \bar{u}_{1}^{R}+2 \bar{v}_{1}^{I} \bar{u}_{1}^{I}-R \bar{\imath}_{0}-e\right)
\end{gathered}
$$

These equations represent the modified averages for index- 0 of the SSSP grid-connected PV system. Without considering the presence of index- 1 terms, these adjusted averages of index- 0 give standard state-space average model of the proposed system. The higher index of the Fourier coefficient might be able to address the higher order harmonics of the state variables.

The average model of the SSSP grid-connected system (5) and (6) can be derived for an index-1 as follows:

$$
\begin{gathered}
\frac{d \bar{v}_{1}}{d t}=-\frac{1}{C} \bar{\imath}_{1}-j \omega_{s} \bar{v}_{1} \\
\frac{d \bar{i}_{1}}{d t}=\frac{1}{L}\left(\overline{v u}_{1}-R i_{1}\right)-j \omega_{s} \bar{\imath}_{1}
\end{gathered}
$$

Similarly, the real and imaginary differential equations to represent the dynamic phasor model for the index-1 can be written as follows:

$$
\begin{gathered}
\frac{d \bar{v}_{1}^{R}}{d t}=-\frac{1}{C}\left(\bar{\imath}_{0} \bar{u}_{1}^{R}+\bar{\imath}_{1}^{R} \bar{u}_{0}\right)+\omega_{s} \bar{v}_{1}^{I} \\
\frac{d \bar{v}_{1}^{I}}{d t}=-\frac{1}{C}\left(\bar{\imath}_{0} \bar{u}_{1}^{I}+\bar{\imath}_{1}^{I} \bar{u}_{0}\right)-\omega_{s} \bar{v}_{1}^{R} \\
\frac{d \bar{\imath}_{1}^{R}}{d t}=-\frac{1}{L}\left(\bar{v}_{0} \bar{u}_{1}^{R}+\bar{v}_{1}^{R} \bar{u}_{0}-R \bar{\imath}_{1}^{R}\right)+\omega_{s} \bar{i}_{1}^{I}
\end{gathered}
$$




$$
\frac{d \bar{\imath}_{1}^{I}}{d t}=-\frac{1}{L}\left(\bar{v}_{0} \bar{u}_{1}^{I}+\bar{v}_{1}^{I} \bar{u}_{0}-R \bar{\imath}_{1}^{I}\right)-\omega_{s} \bar{s}_{1}^{R}
$$

These six differential equations for both indexes represent the detailed dynamics of the SSSP grid-connected PV system. These equations in the standard state-space representation will have the following structure:

$$
\frac{d}{d t}\left[\begin{array}{l}
\bar{\alpha}_{0} \\
\bar{\beta}_{1}
\end{array}\right]=\left[\begin{array}{ll}
A_{11} & A_{12} \\
A_{21} & A_{22}
\end{array}\right]\left[\begin{array}{l}
\bar{\alpha}_{0} \\
\bar{\beta}_{1}
\end{array}\right]+\left[\begin{array}{l}
B \\
0
\end{array}\right] \iota_{p v}
$$

These state variables have separated into two different sets, $\bar{\alpha}_{0}$ define the set of state variables for index- 0 and $\bar{\beta}_{1}$ define the set of state variables for index- 1 as defined in the following:

$$
\bar{\alpha}_{0}=\left[\begin{array}{c}
\bar{v}_{0} \\
\bar{\imath}_{0}
\end{array}\right] \quad \& \quad \bar{\beta}_{1}=\left[\begin{array}{c}
\bar{v}_{1}^{R} \\
\bar{v}_{1}^{I} \\
\bar{i}_{1}^{R} \\
\bar{\imath}_{1}^{I}
\end{array}\right]
$$

The standard state-space model as represented by Equation (31) with the six differential equations in (23) and (30) defines the matrices $A_{11}$ through $A_{22}$ and $B$ the vector as follows:

$$
\begin{gathered}
A_{11}=\left[\begin{array}{cc}
0 & -\frac{1}{C} \\
\frac{\bar{u}_{0}}{L} & -\frac{R}{L}
\end{array}\right], \quad A_{12}=\left[\begin{array}{cccc}
0 & 0 & -\frac{2 \bar{u}_{1}^{R}}{C} & -\frac{2 \bar{u}_{1}^{I}}{C} \\
\frac{2 \bar{u}_{1}^{R}}{L} & \frac{2 \bar{u}_{1}^{I}}{L} & 0 & 0
\end{array}\right] \\
A_{21}=\left[\begin{array}{cc}
0 & -\frac{\bar{u}_{1}^{R}}{\bar{u}_{1}^{I}} \\
0 & -\frac{\bar{u}_{1}}{C} \\
\frac{\bar{u}_{1}^{R}}{L} & 0 \\
\frac{\bar{u}_{1}^{I}}{L} & 0
\end{array}\right], \quad A_{22}=\left[\begin{array}{cccc}
0 & \omega & -\frac{\bar{u}_{0}}{C} & 0 \\
-\omega & 0 & 0 & -\frac{\bar{u}_{0}}{C} \\
\frac{\bar{u}_{0}}{L} & 0 & -\frac{R}{L} & \omega_{s} \\
0 & \frac{\bar{u}_{0}}{L} & -\omega_{s} & -\frac{R}{L}
\end{array}\right] \quad \& \quad B=\left[\begin{array}{c}
\frac{1}{C} \\
0
\end{array}\right]
\end{gathered}
$$

The sub-matrix $A_{11}, A_{12}, A_{21}$ and $A_{22}$ are the constitutional elements of matrix $A$. This matrix structure exhibits extensive analytical properties and the dynamic stability of the SSP grid-connected PV system is analyzed using both eigenvalue analysis and time-domain simulation results along with the corresponding frequency-domain analysis. The stability analysis of the SSSP grid-connected PV system using the eigenvalue analysis is discussed in the following section.

\section{Stability Analysis Using Eigenvalue}

The duty ratio of the associated full-bridge DC-AC converter of the SSSP grid-connected PV system enters this model through the switching control input $u(t)$. If the duty ratio of the inverter, $d$ is 0.5 then the index- 0 and index- 1 becomes $\bar{u}_{0}=d, \bar{u}_{1}^{R}=\frac{1}{2 \pi} \sin (2 \pi d)$ and $\bar{u}_{1}^{I}=\frac{1}{2 \pi}(\sin (2 \pi d)-1)$. We shall consider the SSSP grid-connected PV system in Figure 1 with the its parameters as $R=1 \Omega$, $L=100 \mu \mathrm{H}$, and $\mathrm{C}=40 \mu \mathrm{F}$.

As mentioned in the previous section, Equation (26) represents the dynamic phasor averaging model of the SSSP grid-connected PV system. This modified mathematical model offers a great investigation platform to obtain the solution. For the proposed system, the eigenvalues of $6 \times 6$ characteristic matrix A in Equation (31) under different switching frequencies are shown following Table 1.

In Table 1 , the first two and other four eigenvalues in all columns have come from index- 0 and index-1, respectively. The eigenvalues of matrix $A$ are also closely estimated through sub-matrices $A_{11}$ and $A_{22}$ separately. The evaluating formula for eigenvalues of sub-matrices $A_{11}$ and $A_{22}$ are derived as discussed in the following. 
Table 1. Eigenvalues of the SSSP grid-connected PV system at different switching frequencies.

\begin{tabular}{cccc}
\hline Index \& Switching Frequency & $f_{s}=\mathbf{1 0} \mathbf{~ k H z}$ & $f_{s}=\mathbf{2 0} \mathbf{~ k H z}$ & $f_{s}=\mathbf{5 0 ~} \mathbf{~ k H z}$ \\
\hline \multirow{2}{*}{$k=0$} & $(-0.0503+0.0620 i) \times 10^{5}$ & $(-0.0501+0.0614 i) \times 10^{5}$ & $(-0.0500+0.0613 i) \times 10^{5}$ \\
\cline { 2 - 4 } & $(-0.0503-0.0620 i) \times 10^{5}$ & $(-0.0501-0.0614 i) \times 10^{5}$ & $(-0.0500-0.0613 i) \times 10^{5}$ \\
\hline \multirow{3}{*}{$k=1$} & $(-0.0506+0.6929 i) \times 10^{5}$ & $(-0.0504+1.3195 i) \times 10^{5}$ & $(-0.0502+3.2035 i) \times 10^{5}$ \\
\cline { 2 - 4 } & $(-0.0506-0.6929 i) \times 10^{5}$ & $(-0.0504-1.3195 i) \times 10^{5}$ & $(-0.0502-3.2035 i) \times 10^{5}$ \\
\hline & $(-0.0490+0.5696 i) \times 10^{5}$ & $(-0.0495+1.1968 i) \times 10^{5}$ & $(-0.0498+3.0809 i) \times 10^{5}$ \\
\hline & $(-0.0490-0.5696 i) \times 10^{5}$ & $(-0.0495-1.1968 i) \times 10^{5}$ & $(-0.0498-3.0809 i) \times 10^{5}$ \\
\hline
\end{tabular}

Two eigenvalues provide sub-matrix $A_{11}$ in index- 0 as below:

$$
\lambda_{1,2}(A 11)=-a \pm j \sqrt{b^{2}-a^{2}}
$$

Four eigenvalues provide sub-matrix $A_{22}$ in index-1 as below:

$$
\begin{gathered}
\lambda_{1,2}(A 22)=-a \pm j\left(\omega_{s}+\sqrt{b^{2}-a^{2}}\right) \\
\lambda_{3,4}(A 22)=-a \pm j\left(-\omega_{s}+\sqrt{b^{2}-a^{2}}\right)
\end{gathered}
$$

where $a=\frac{R}{2 L}, b=\frac{\bar{u}_{0}}{\sqrt{L C}}$ and $\omega_{s}=2 \pi f_{s}$.

Table 2 shows the eigenvalues for the decoupled sub-matrices $A_{11}$ and $A_{22}$ which are almost like the eigenvalues of the full matrix $A$. Hence, it can be said that the dynamic phasor averaging technique has the decoupling property of the characteristic matrix $A$. In addition, this technique has shown that the imaginary part of eigenvalues becomes larger with the increases in the switching frequency for index-1. The time-domain simulation along with the frequency-domain results are discussed in the following section.

Table 2. Eigenvalues of the SSSP grid-connected PV system at different switching frequencies through Equations (32)-(34).

\begin{tabular}{cccc}
\hline Index \& Switching Frequency & $f_{s}=\mathbf{1 0} \mathbf{~ k H z}$ & $f_{s}=\mathbf{2 0} \mathbf{~ k H z}$ & $f_{s}=\mathbf{5 0 ~} \mathbf{~ k H z}$ \\
\hline \multirow{2}{*}{$k=0$} & $(-0.0500+0.0612 i) \times 10^{5}$ & $(-0.0500+0.0612 i) \times 10^{5}$ & $(-0.0500+0.0612 i) \times 10^{5}$ \\
\cline { 2 - 4 } & $(-0.0500-0.0612 i) \times 10^{5}$ & $(-0.0500-0.0612 i) \times 10^{5}$ & $(-0.0500-0.0612 i) \times 10^{5}$ \\
\hline \multirow{3}{*}{$k=1$} & $\frac{(-0.0500+0.6895 i) \times 10^{5}}{(-0.0500-0.6895 i) \times 10^{5}}$ & $(-0.0500+1.3179 i) \times 10^{5}$ & $(-0.0500+3.2028 i) \times 10^{5}$ \\
\hline & $\frac{(-0.0500+0.5670 i) \times 10^{5}}{(-0.0500-0.5670 i) \times 10^{5}}$ & $(-0.0500+1.3179 i) \times 10^{5}$ & $(-0.0500-3.2028 i) \times 10^{5}$ \\
\hline & & $(-0.0500-1.1954 i) \times 10^{5}$ & $(-0.0500-3.0803 i) \times 10^{5}$ \\
\hline
\end{tabular}

\section{Stability Analysis through Simulation Results}

The performance of the dynamic phasor model of the SSSP grid-connected PV system with the open-loop is analyzed in MATLAB. This section will provide an idea about the necessity of the dynamic phasor averaging model for the proposed system. The change in the model depending on the switching frequency in a full-bridge inverter for the SSSP grid-connected PV system is analyzed here.

The time-domain results of the existing state-space and proposed dynamic phasor averaging approach for the SSSP grid-connected PV system are compared in Figure 2 through the step response of the inverter. The open-loop step responses for power electronic converters change with variations in the switching frequency. However, the state-space averaging technique does not allow the switching frequency of converters as a part of mathematical representation. For this reason, the output response of the device is fixed. The dynamic phasor averaging mathematical representation of the power electronic converter has sensitivity to the switching frequency, which can be clearly seen from Figure $2 b$. 


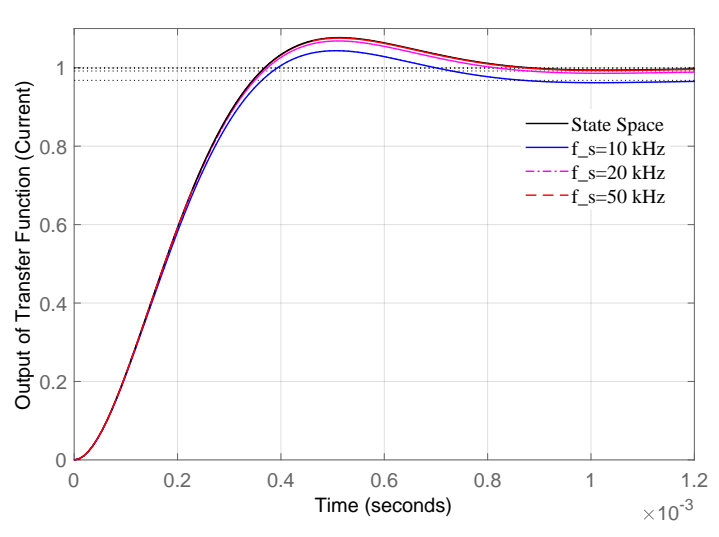

(a) Step response

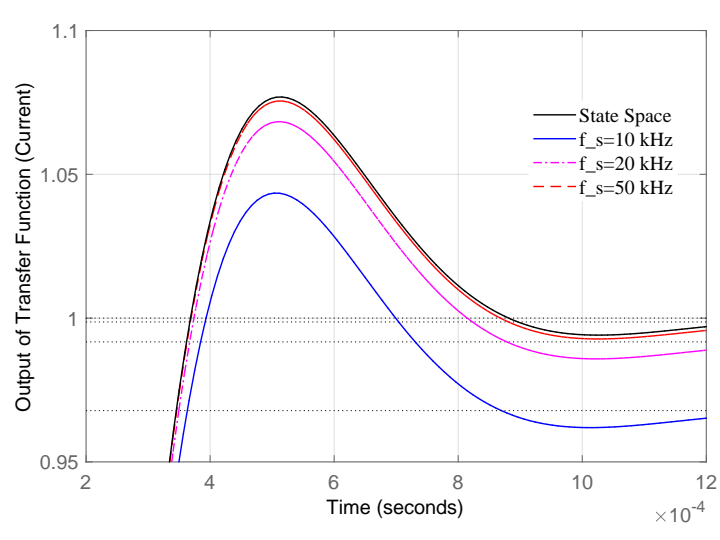

(b) Zoomed a

Figure 2. Open-loop step response for the SSSP grid-connected PV system at different switching frequencies.

Figure 3 shows the Bode plots of the open-loop system under different switching frequencies which are also compared with the state-space averaging model, where $i_{p v}$ and $i$ are input and output variables of the system, respectively. The conventional technique is not capable of demonstrating the sensitivity to switching frequencies as shown in Figure $3 b$.

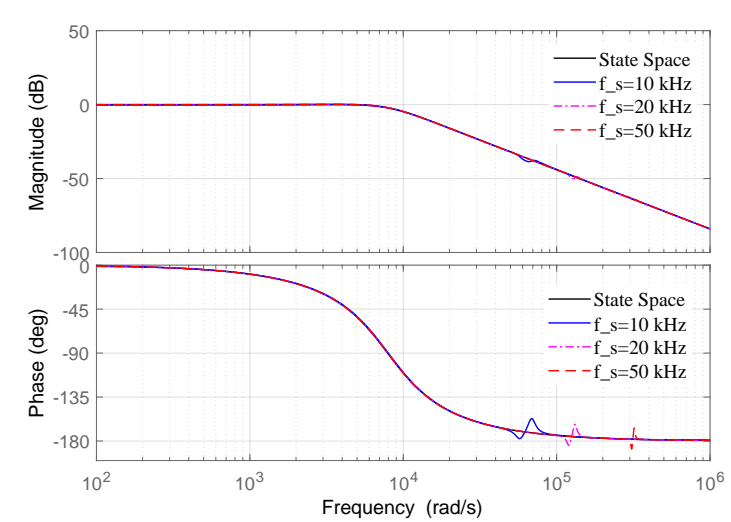

(a) Bode plot

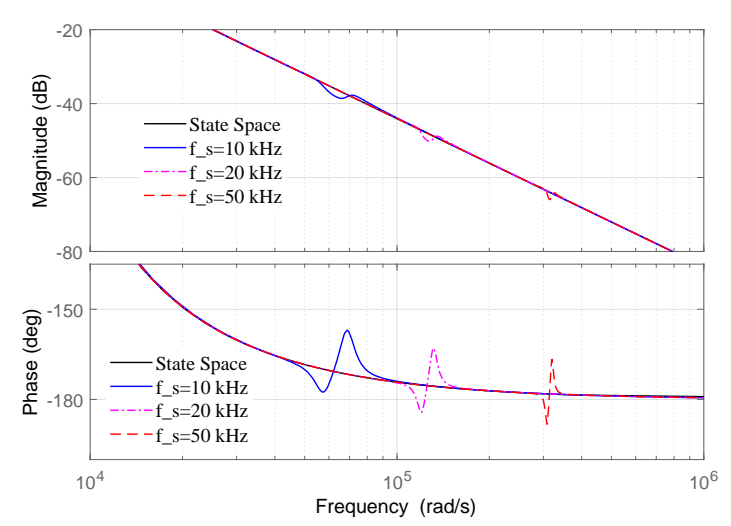

(b) Zoomed a

Figure 3. Bode plot for the open-loop SSSP grid-connected PV system at different switching frequency.

The power electronics converters are high-frequency switching devices, where their frequencies are selected randomly for the conventional SSA model, which may affect the stability of the system. Figure 4 shows the locus of roots of the SSSP grid-connected PV system using the root-locus stability analysis tool. Each locus entry on the positive side of the horizontal axis increases with higher switching frequencies, which is an issue that needs to be addressed in the design of a proper controller for the system's reliable operation, whereas the designed SSA approach does not depend on the switching frequency. 


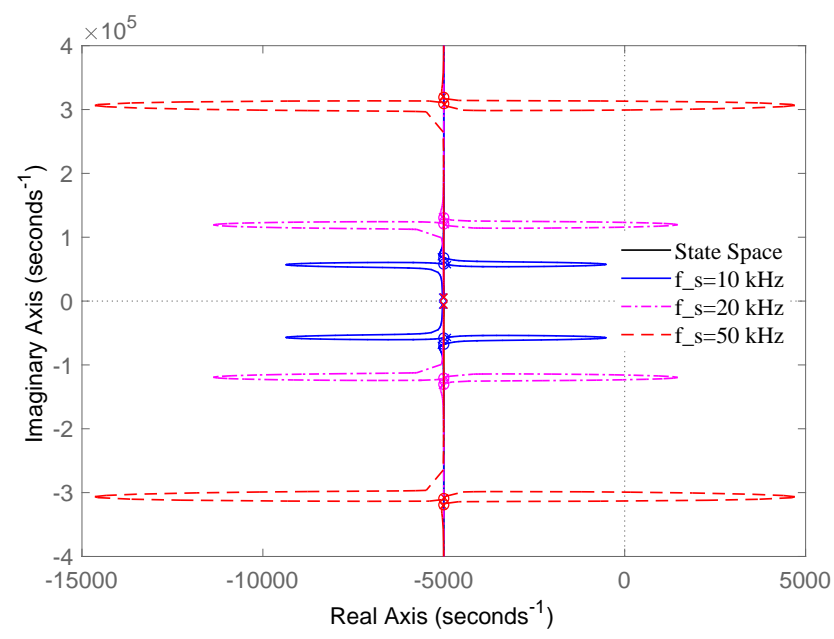

Figure 4. Root-locus of open-loop SSSP grid-connected PV system at different switching frequency.

\section{Conclusions}

The dynamic phasor averaging approach proposed in this paper has some advantages over conventional SSA methods for modeling a SSSP grid-connected PV system. This mathematical representation technique extends the second-order to sixth-order model of the proposed system. The dynamic phasor averaging technique is independent of the switching frequency, which can give a better approximation of the SSSP grid-connected PV system. In this paper, transient stability analysis is done and the effects of different switching frequencies on the dynamical model are analyzed. A proper mathematical model is essential to enhance the transient stability of SSSP grid-connected PV systems, where the designed dynamic phasor averaging will provide a convenient dynamical model to design a controller for reliable operation. In future work, the proposed dynamic phasor averaging model will be used to design a controller to enhance the transient stability of the grid-connected PV system.

Author Contributions: M.R.M. has formulated the mathematical model, and conducted all simulation studies and put the results together along with the detailed analysis. A.F.A. was providing some suggestions during writing the paper through wise discussions and doing revisions. H.P. was responsible for generating the key idea in the paper, and finalizing the draft and doing revisions.

Funding: This research received no external funding.

Conflicts of Interest: The authors declare no conflict of interest.

\section{References}

1. Eftekharnejad, S.; Vittal, V.; Heydt, G.T.; Keel, B.; Loehr, J. Impact of increased penetration of photovoltaic generation on power systems. IEEE Trans. Power Syst. 2013, 28, 893-901. [CrossRef]

2. Shah, D.G.; Crow, M. Stability design criteria for distribution systems with solid-state transformers. IEEE Trans. Power Deliv. 2014, 29. [CrossRef]

3. Emadi, A.; Khaligh, A.; Rivetta, C.H.; Williamson, G.A. Constant power loads and negative impedance instability in automotive systems: Definition, modeling, stability, and control of power electronic converters and motor drives. IEEE Trans. Veh. Technol. 2006, 55, 1112-1125. [CrossRef]

4. Riccobono, A.; Cupelli, M.; Monti, A.; Santi, E.; Roinila, T.; Abdollahi, H.; Arrua, S.; Dougal, R.A. Stability of shipboard dc power distribution: Online impedance-based systems methods. IEEE Electrif. Mag. 2017, 5, 55-67. [CrossRef]

5. Chiniforoosh, S.; Jatskevich, J.; Yazdani, A.; Sood, V.; Dinavahi, V.; Martinez, J.; Ramirez, A. Definitions and applications of dynamic average models for analysis of power systems. IEEE Trans. Power Deliv. 2010, 25, 2655-2669. [CrossRef]

6. Bui, L.; Casoria, S.; Morin, G.; Reeve, J. EMTP TACS-FORTRAN interface development for digital controls modeling. IEEE Trans. Power Syst. 1992, 7, 314-319. [CrossRef] 
7. Dommel, H.W. Digital computer solution of electromagnetic transients in single-and multiphase networks. IEEE Trans. Power Appar. Syst. 1969, PAS-88, 388-399. [CrossRef]

8. Dommel, H.W. Electromagnetic Transients Program: Reference Manual (EMTP Theory Book); Bonneville Power Administration: Portland, OR, USA, 1986.

9. Hannan, M.; Chan, K. Modern power systems transients studies using dynamic phasor models. In Proceedings of the 2004 International Conference on Power System Technology (PowerCon 2004), Singapore, 21-24 November 2004; Volume 2, pp. 1469-1473.

10. Tadmor, G. On approximate phasor models in dissipative bilinear systems. IEEE Trans. Circuits Syst. Fundam. Theory Appl. 2002, 49, 1167-1179. [CrossRef]

11. Mohan, N.; Undeland, T.M. Power Electronics: Converters, Applications, And Design; John Wiley \& Sons: Hoboken, NJ, USA, 2007.

12. Mahmud, M.; Pota, H.; Hossain, M. Nonlinear current control scheme for a single-phase grid-connected photovoltaic system. IEEE Trans. Sustain. Energy 2014, 5, 218-227. [CrossRef]

13. Mahmud, M.A.; Pota, H.; Hossain, M. Dynamic stability of three-phase grid-connected photovoltaic system using zero dynamic design approach. IEEE J. Photovolt. 2012, 2, 564-571. [CrossRef]

14. Mahmud, M.; Pota, H. Robustness Analysis of $H_{\infty}$ Controller for Feedback Linearized Model of Grid Connected Inverter. In Proceedings of the 2018 IEEE International Conference on Power Electronics, Drives and Energy Systems (PEDES), Chennaik, India, 18-21 December 2018; pp. 1-6.

15. Sanders, S.R.; Noworolski, J.M.; Liu, X.Z.; Verghese, G.C. Generalized averaging method for power conversion circuits. IEEE Trans. Power Electron. 1991, 6, 251-259. [CrossRef]

16. Caliskan, V.A.; Verghese, O.; Stankovic, A.M. Multifrequency averaging of DC/DC converters. IEEE Trans. Power Electron. 1999, 14, 124-133. [CrossRef]

17. Emadi, A. Modeling of power electronic loads in ac distribution systems using the generalized state-space averaging method. IEEE Trans. Ind. Electron. 2004, 51, 992-1000. [CrossRef]

18. Stefanov, P.C.; Stankovic, A.M. Modeling of UPFC operation under unbalanced conditions with dynamic phasors. IEEE Trans. Power Syst. 2002, 17, 395-403. [CrossRef]

19. Qi, Q.; Yu, C.; Wai, C.K.; Ni, Y. Modeling and simulation of a STATCOM system based on 3-level NPC inverter using dynamic phasors. In Proceedings of the IEEE Power Engineering Society General Meeting, Denver, CO, USA, 6-10 June 2004; pp. 1559-1564.

20. Yao, W.; Wen, J.; He, H.; Cheng, S. Modeling and simulation of VSC-HVDC with dynamic phasors. In Proceedings of the 2008 Third International Conference on Electric Utility Deregulation and Restructuring and Power Technologies, Nanjing, China, 6-9 April 2008; pp. 1416-1421.

21. Chudasama, M.C.; Kulkarni, A.M. Dynamic phasor analysis of SSR mitigation schemes based on passive phase imbalance. IEEE Trans. Power Syst. 2010, 26, 1668-1676. [CrossRef]

22. Patel, D.C.; Chandorkar, M. Small-signal transient analysis of induction machines with stator inter-turn faults using dynamic phasors. In Proceedings of the 2012 IEEE Energy Conversion Congress and Exposition (ECCE), Raleigh, NC, USA, 15-20 September 2012; pp. 3008-3015.

23. Nagarajan, A.; Ayyanar, R. Dynamic phasor model of single-phase inverters for analysis and simulation of large power distribution systems. In Proceedings of the 2013 4th IEEE International Symposium on Power Electronics for Distributed Generation Systems (PEDG), Rogers, AR, USA, 8-11 July 2013; pp. 1-6.

24. Coronado-Mendoza, A.; Pérez-Cisneros, M.A.; Domínguez-Navarro, J.A.; Osuna-Enciso, V.; Zúñiga-Grajeda, V.; Gurubel-Tun, K.J. Dynamic phasors modeling for a single phase two stage inverter. Electr. Power Syst. Res. 2016, 140, 854-865. [CrossRef]

(C) 2019 by the authors. Licensee MDPI, Basel, Switzerland. This article is an open access article distributed under the terms and conditions of the Creative Commons Attribution (CC BY) license (http://creativecommons.org/licenses/by/4.0/). 